\title{
A alma e o cérebro: as origens do debate acerca da Psicologia científica no Brasil
}

\section{The soul and the brain: the origins of the discussions on scientific Psychology in Brazil}

\section{Leonardo Ferreira Almada*}

Professor adjunto da Faculdade de Filosofia da Universidade Federal de Goiás -UFG, Goiânia, GO, Brasil

\section{Luiz Alberto Cerqueira}

Professor Associado do Departamento de Filosofia da Universidade Federal do Rio de Janeiro - UFRJ, Rio de Janeiro, RJ, Brasil

\begin{abstract}
RESUMO
Neste artigo, meu objetivo é o de apontar para a significação dos primeiros debates acerca da natureza da Psicologia Científica no Brasil. Para tanto, trabalharei com textos de dois autores em especial, Gonçalves de Magalhães e Tobias Barreto. Meu interesse é o de demonstrar em que sentido estes filósofos foram capazes de oferecer oposição a uma tendência positiva vigente na Psicologia e, ao mesmo tempo, superar o caráter contemplativo da consciência de si inerente à Psicologia sob a égide dos Jesuítas, e em vista da necessidade de modernização filosófica no Brasil. Ao mesmo tempo, pretendo mostrar que, a despeito da crítica de Tobias a Magalhães, ambos souberam reconhecer a significação do naturalismo em Psicologia, especialmente no que diz respeito à tarefa de inserir o pensamento brasileiro nos rumos da filosofia ocidental.
\end{abstract}

Palavras-Chave: Consciência de si, Psicologia e ciência, Filosofia e psicologia, Modernização.

\begin{abstract}
In this paper, my aim is to point to the significance of the earlier discussions about the nature of Scientific Psychology in Brazil. Therefore, I will work in particular with texts of two authors, Gonçalves de Magalhães and Tobias Barreto. My interest it to demonstrate in what sense these philosophers were able to offer opposition to a current positive trend in Psychology and the same time, overcome the contemplative character of self-consciousness inherent in Psychology under the aegis of the Jesuits, in view of need for philosophical modernization in Brazil. At the same time, I intend to show that, despite the criticism of Tobias to Magalhães, both know recognize the significance of the naturalism in Psychology, especially with regard to the task of entering the Brazilian thought in the course of Western Philosophy.

Keywords: Self-consciousness, Psychology and science, Philosophy and psychology, Modernization.
\end{abstract}

\section{A necessidade de superação do caráter contemplativo da Psicologia sob a égide dos Jesuítas Elaboradas em meados do século XIX, as obras de Domingos José}


Gonçalves de Magalhães refletem um espírito vigoroso dedicado a promover a modernização no Brasil. Como evidência disto, há o reconhecimento histórico e literário de que foi ele quem realizou, com a publicação de Suspiros poéticos e saudades (1836), a reforma da literatura brasileira mediante a introdução do romantismo. Mais do que isto, porém, interessa-nos ressaltar dois aspectos de sua obra modernizadora. Um, que diz respeito à ideia de modernização, a saber, que ele foi o primeiro a pensar a necessidade de reformas a partir de nossa própria experiência histórico-cultural; o outro, que diz respeito à tarefa que ele mesmo se propôs em face da tradição filosófica brasileira sob a Ratio Studiorum, a saber: superar, no âmbito de uma educação marcada pela religiosidade, o caráter contemplativo e infecundo do conhecimento de si, sem deixar, entretanto, de reconhecer-Ihe a significação transcendente. Deste segundo aspecto, ele trata principalmente em suas obras Fatos do espírito humano (1858) e A alma e o cérebro (1876).

Visando a superar, e por isso mesmo, sem descartar a contemplatividade como um estágio da vida teórica, Magalhães consagra definitivamente no Brasil um sentido de "consciência de si" como inteligência e liberdade no sujeito concreto e histórico. Trata-se da adesão à moderna noção ontológica de liberdade inerente ao cogito cartesiano, o que implica a superação do paradigma da indiferença da vontade que marca o sentido contemplativo de liberdade em face da fé. Assim se caracteriza, no Brasil, a modernização da "ciência" da alma ou espírito como fundamento do modo do ser do homem de ação, e não apenas de contemplação, em que a vontade se revela apenas como indiferença na escolha de um ou outro dos contrários. Essa "consciência e liberdade the dão uma individualidade real, a posse de si mesmo, e ele diz eu [...]. Por essa consciência individual, e por seus próprios atos, é que ele se julga, e é julgado" (MAGALHÃES, 2004, p. 354). Segundo Cerqueira (2002, p. 114), "Magalhães é o primeiro brasileiro a assumir atitude teórica em face da filosofia moderna e a partir do aristotelismo constituinte de sua própria tradição". Trata-se, pois, da substituição do papel da conversão religiosa como origem da autoconsciência por um sentido de consciência de si à luz da razão: "só tem liberdade nesse mundo quem é inteligente; só tem inteligência quem é livre, e obra por si mesmo; e quem tem inteligência e liberdade tem consciência de si mesmo, e é de necessidade um ente moral" (MAGALHÃES, 2004, p. 355).

A filosofia brasileira, assim fundada, define sua identidade no cenário da filosofia ocidental exatamente em função desta característica que será a marca axial de seus representantes, a saber: 0 reconhecimento de que as reformas não implicam a descaracterização da própria ideia de filosofia em sua historicidade. É deste modo que Magalhães, apontando para um sentido intrínseco e real de liberdade, 
denunciou o abuso da razão na contemplatividade, sempre que da razão fazemos uso ilimitado em vista de nos "sentirmos livres da necessidade mecânica que o nosso próprio corpo e os sentidos do corpo nos impõem por natureza" (MAGALHÃES, 2004, p. 355). Se desde a irrupção da filosofia e ciência modernas nada justifica um sentido meramente contemplativo da autoconsciência, por outro lado, todavia, nada também justifica que, em nome dos princípios e conquistas da Revolução Científica, fique asfixiada a significação transcendente da consciência de si.

\section{Corporeidade e consciência de si: a questão da liberdade}

É visando a essa conciliação que Magalhães, apoiado no sentido de consciência de si como inteligência e liberdade, erige a tese segundo a qual a corporeidade está a serviço da consciência de si. Assim, quando defende, sobretudo no livro XIII de Fatos do Espírito Humano, a separação entre alma e corpo em vista do conhecimento de si, isso não quer dizer que se assemelha ao modo como na vida contemplativa se estabelece uma separação entre consciência e corporeidade. Afinal, a moralidade depende da sujeição à corporeidade: "só com essa triste condição poderíamos ser entes morais". Esta "triste condição" aponta exatamente para a compreensão cartesiana de que é o domínio da corporeidade que propicia ao homem a consciência de si como ser finito e dependente em face do ser infinito e independente, isto é, a compreensão de criatura "sujeito a leis necessárias, independentes da nossa vontade" (MAGALHÃES, 2004, p. 355). Por outro lado, é no mesmo reino da corporeidade que o indivíduo, revestido de uma vontade muito maior que o entendimento, é capaz de estender a vontade às coisas que não conhece, uma vez que "o corpo não nos foi dado como uma condição de saber e de querer" (MAGALHÃES, 2004, p. 355). O que esta "triste condição" nos mostra é que, de um modo ou de outro, toda vida psíquica do indivíduo está fundada na corporeidade, sobretudo porque o corpo nos foi dado "como uma sujeição que coarctasse esse poder livre [o livre arbítrio] de que abusaríamos, chamando-nos à vida prática" (MAGALHÃES, 2004, p. 355).

De pleno acordo com Descartes quanto à opinião de que no ser humano a inteligência é muito limitada e a vontade ilimitada, Magalhães, também aqui sem prejuízo de nossas fontes filosóficas sob a Ratio Studiorum, conclui que toda a discordância deriva do concurso da inteligência e do livre arbítrio, "porque bastariam estas duas condições para que cada indivíduo pensasse, discorresse, e quisesse ordenar as coisas a seu jeito [...] e não haveria acordo" (MAGALHÃES, 2004, p. 355).

Qual é, pois, o papel exercido pela corporeidade quanto à possibilidade de realizar ações morais? Segundo Magalhães, tal significação se expressa no fato de que tudo o que "convém ao corpo 
é anunciado pelos apetites e desejos periódicos, que não dependem de cálculo algum, e cuja satisfação natural nos dão prazeres, e pode dar-nos algum mérito, combatendo-os quando desordenados, e tendentes a embrutecer-nos" (MAGALHÃES, 2004, p. 362). Em vista da superação do espírito contemplativo, Magalhães enfatiza o papel do corpo animal, enquanto o que limita o poder do saber e do querer absolutos. É pelo corpo que se explica a limitação do poder humano, e é por meio dele que reconhecemos nossa finitude e dependência em face do ser infinito e independente. Em outras palavras, reconhecemo-nos enquanto um ser "sujeito a leis necessárias, independentes da nossa vontade, que demanda imperiosamente a nossa atenção, e involuntariamente se opõe às nossas determinações" (MAGALHÃES, 2004, p. 354).

A importância concedida à vida prática é o que nos autoriza afirmar com convicção em que sentido Magalhães propõe a superação da vida contemplativa. Sem dúvida, a capacidade moral de querer as coisas que pela inteligência vislumbramos como certas não se compatibiliza com a vida contemplativa, justamente por envolver a seguinte questão: "como é possível que o ser humano seja capaz de prever pela inteligência a realidade de algo sem assumir, de certo modo, que é também responsável pela sua existência?" (CERQUEIRA, 2006, p. 15). No paradigma contemplativo, o sujeito ainda não é capaz de agir sem que, para tanto, nenhuma força exterior o obrigue a tanto. É neste sentido que a fé, para Magalhães, se constitui no mais baixo grau de liberdade.

\section{Consciência de si como inteligência e liberdade: o problema da psicologia científica}

O sentido completo de liberdade, pois, só se realiza no momento em que o indivíduo, impelido pelo peso de alguma razão, seja capaz de aderir de modo irresistível a um dos lados contrários. Com efeito, se há a exigência de superação da indiferença, isso não ocorre senão em virtude do fato de que não há qualquer fator externo que nos obrigue a agir de tal modo. O sentido de consciência de si como inteligência e liberdade relaciona-se com o problema da indiferença na medida em que se eu conhecesse claramente o que é verdadeiro e o que é bom, nunca estaria em dificuldade para deliberar que juízo ou escolha deveria fazer; e assim seria inteiramente livre sem nunca ser indiferente. Desse modo, o erro humano independe de sua natureza, isto é, do fato de termos sido criados por Deus, mas, antes, depende de nossa própria ação ou do uso da liberdade, haja vista que nossa natureza é a mesma quando julgamos quer correta quer incorretamente. O poder humano, diferentemente do de Deus, que é absoluto e livre no mais alto grau, é imensamente limitado. Mas, contrariamente ao que apregoa a frenologia, nenhum argumento fundado na corporeidade e na existência real do fatalismo inviabiliza 
a liberdade humana.

Assim se compreende em que sentido os propósitos filosóficos de Magalhães se realizam em oposição à redução do indivíduo e dos atos da consciência ao puro mecanismo da corporeidade. Tal é o motivo pelo qual a compreensão da posição de Magalhães depende do seguinte reconhecimento: sua distância de um sentido extrínseco de liberdade implica, na mesma medida, o entendimento de que a liberdade de querer não se incompatibiliza com a necessidade. Ora, a então nascente psicologia experimental - assumindo as mesmas consequências do liberalismo e das acepções de Hume e de Hobbes, que se apoiaram em um sentido meramente extrínseco de liberdade - tornou incompatível a liberdade de querer com a necessidade, na medida em que vinculou a liberdade ao âmbito natural, isto é, como fenômeno da natureza e, portanto, de acordo com a causalidade mecânica a que se reduzem as leis da física. Em Magalhães, porém, a despeito da impossibilidade de definir esse sentido intrínseco de liberdade - inerente à consciência de si - em separado do sentido da necessidade inerente aos fenômenos físicos, a noção que reduz a consciência ao puro mecanismo da corporeidade não se justifica senão enquanto resultante de suposições filosóficas inteiramente equívocas.

De fato, a compreensão de homem a partir de sua sujeição à causalidade mecânica é uma consequência da tese reducionista que, em vista de um eu meramente fenomenal e psicofísico, estabelece o cérebro como origem da alma e fonte única de todos os nossos atos sensíveis, intelectuais e morais. Trata-se de uma concepção de cérebro como órgão da inteligência, consciência e liberdade que engendra a tese naturalista consoante a qual é o cérebro o órgão destinado a produzir pensamento, isto é, a secretar o pensamento do mesmo modo que os outros órgãos secretam humores (MAGALHÃES, 1867, p. 22). É em função destes resultados do naturalismo que Magalhães, propondo-se definir o espírito e distingui-lo do que "não é ele nem dele" mediante a separação de alma e corpo, assume o propósito de constituir a delimitação formal de uma orientação a qual vá de encontro aos princípios da tese reducionista: "distinguir-se dele [do corpo] é distinguir-se de tudo"; é pois dele, do seu próprio corpo, que não é ele nem dele, "que o espírito há de se estremar, para conhecer a sua própria natureza, a sua origem e seu destino" (MAGALHÃES, 2004, p. 293). É nesse mesmo sentido que se compreendem as afirmações de Magalhães de que "a base e o ponto de partida de todas as ciências filosóficas é a psicologia, da qual elas são ampliações e aplicações"; de que os sucessores de Gall, ao tentarem considerar "o cérebro como órgão multíplice da inteligência", nada provaram contra a existência de uma alma "indivisível, simples e idêntica"; e, finalmente, de que "a teoria do puro sensualismo não nos explica nem mesmo uma sensação, quanto 
mais todos os nossos conhecimentos" (MAGALHÃES, 2004, p. 108).

\section{Algumas concessões e delimitações dos equívocos inerentes à psicologia naturalizada}

Sem deixar de levar em consideração a exigência de conciliação entre filosofia e ciência, e sem deixar de reconhecer que algumas faculdades da alma dependem do concurso do organismo, especialmente do cérebro enquanto centro do sistema nervoso, Magalhães também não deixa de reconhecer os prejuízos inerentes às consequências filosóficas de uma psicologia aos moldes das ciências naturais. Ora, a completa subordinação das faculdades da alma a funções orgânicas - mediante a distribuiç̧ão e classificação das faculdades intelectuais e morais pelas diversas circunvoluções do cérebro - é o que justifica a dissolução da crença na identidade pessoal que se revela na consciência, isto é, no âmbito da variedade de seus atos, e na contínua renovação de seus órgãos. Afinal, a redução das faculdades da alma a funções orgânicas elimina a unidade do sujeito atestada pela consciência, isto é, "a mesmidade do sujeito que se revela na consciência" (MAGALHÃES, 1867, p. 74). Conforme Magalhães, a supressão da identidade pessoal por meio da ideia de cérebro como órgão da inteligência, da consciência e da liberdade é o resultado de uma confusão cuja origem reside no esquecimento de que o cérebro é simplesmente o bulbo "nutritivo dos nervos e o órgão onde as impressões [...] aumentam a intensidade e duram, a fim de que a vida sensível, sem consciência e sem senhorio de si mesma, possa [...] continuar a sua operação começada" (MAGALHÃES, 2004, p. 154).

Como procura demonstrar Magalhães, que também era médico, esta confusão da psicofísica e da psicofisiologia tem início em uma má interpretação quanto às relações entre cérebro e pensamento, originada, por sua vez, no fato de que, embora não possamos reduzir - espírito à atividade cerebral, é o cérebro sem dúvida um instrumento do espírito, por nele se concentrar todas as impressões necessárias para as múltiplas sensações, percepções e sentimentos. De fato, todas as impressões são transmitidas pelos nervos ao cérebro, o órgão que conserva e coordena todas as impressões ações necessárias ao uso da memória - e que estão ou podem estar no cérebro sem que delas tenhamos consciência, como não temos deste órgão material nem de alguma coisa material. Nesse sentido, compreendemos a afirmação de Magalhães consoante a qual "nenhum espiritualista antigo ou moderno pretendeu jamais que não precisa nossa alma neste mundo de olhos para ver e de ouvidos para ouvir". Pelo contrário, muitos até "consideraram o cérebro em geral como indispensável para o exercício do pensamento; e da existência e necessidade desses e de outros órgãos do corpo não sai triunfante o materialismo" (MAGALHÃES, 1867, p. 31): 
Para os mais escrupulosos, e que não veem a menor semelhança entre o produto material dos intestinos e do fígado, e os atos de consciência, o cérebro é apenas o instrumento de cujo concurso necessita o espírito para exercer e revelar as suas diversas faculdades (MAGALHÃES, 1867, p. 22).

Sem dúvida, as afecções cerebrais podem alterar a saúde do corpo, modificando e perturbando o tipo normal das impressões, gerando alterações nas sensações correspondentes, bem como nos atos da memória que de tais impressões e sensações dependem. As afecções do cérebro, por isso mesmo, podem gerar certas confusões nos juízos e nas palavras. De certo modo, portanto, o espírito guarda alguma dependência do cérebro, mas da mesma forma que o cérebro depende do coração e do sangue que dele recebe; do mesmo modo que se depende do pulmão para a oxigenação do sangue; e da mesma maneira que todos os órgãos do corpo dependem uns dos outros. Nem por isso, porém, podemos dizer que o cérebro é o produtor da inteligência; de onde se segue que as faculdades mentais são claramente distintas dos órgãos vitais que as exercem como instrumento.

Com efeito, há, além do cérebro, alguma coisa requerida quanto à explicação dessas faculdades. Há uma individualidade idêntica, que "assume e reúne todas essas faculdades como atos seus próprios, e sem a qual nada perceberíamos, ainda que para o exercício de algumas de suas faculdades necessite do concurso do cérebro". Destarte, ainda que devamos aceitar que o espírito necessite do cérebro como um órgão multíplice "para que se possa exercer e revelar diversas espécies de pensamento e de afecções", nem por isso devemos aceitar que "se materializam as faculdades intelectuais e morais". Ora, quanto mais concebemos uma multiplicidade e variedade de instrumentos, mais fica comprovada a "unidade e identidade do ser que deles se serve, por uma lei providencial que ele ignora, e que não precisa conhecer, nem mesmo saber se tais órgãos existem, para que ele possa exercer as faculdades que the são próprias" (MAGALHÃES, 1867, p. 31). Tal é razão pela qual Magalhães concebe como inescrupulosos os que:

Não julgando possível a existência de outra substância além da material, dando por demonstrado este ponto, como já o estava para os materialistas de todos os tempos independentemente da fisiologia e da química, se não pudessem de nenhum modo localizar o entendimento, e convertê-lo em uma secreção ou movimento do cérebro, nem por isso o deixariam de considerá-lo como um fenômeno da matéria (MAGALHÃES 1867, p. 32). 
Para ele, o homem, que também é corpo, é dotado de uma força vital cujo papel consiste em organizar seus órgãos e lhes conferir sensibilidade. Daí devermos admitir que, em verdade, "sirva o cérebro ao espírito como o piano ao artista que nele executa a música que tem na mente" (MAGALHÃES, 1867, p. 32). Por isso mesmo, não podemos acatar a hipótese materialista que concebe os atos intelectuais e morais em sincronia com as funções do estômago e do fígado, isto é, enquanto produção material do cérebro. No homem, só o espírito é real, fato cuja evidência reporta à indubitável consciência de sua unidade e identidade. Enquanto a matéria se nos apresenta do ponto de vista da extensão, divisibilidade, inércia e sujeita a mudanças sob a ação de agentes naturais, o espírito, em contrapartida, se nos apresenta como consciente, idêntico a si mesmo, sensível, inteligente e livre, o que torna incompatível qualquer hipótese reducionista e qualquer assimilação metodológica:

\begin{abstract}
A consciência da unidade e identidade do ser que pensa, sente e quer é um fato indeclinável, e não uma gratuita hipótese metafísica, de que possamos prescindir no estudo da natureza intelectual e moral do homem. Esse fato da consciência obriga tanto os filósofos como o comum dos homens a atribuir todas as nossas faculdades a um princípio simples, a um mesmo sujeito indivisível, a que chamamos alma ou espírito, para distingui-la do princípio substancial dos fenômenos corpóreos, que se nos apresenta como composto de partes e divisível (MAGALHÃES, 1867, p. 8).
\end{abstract}

Ignorar este fato, como o faz a psicofísica, é reduzir o ser que pensa à suposta substância material; é desprezar, pontua Magalhães, o testemunho indubitável da consciência, para além do qual nada percebemos. A psicologia experimental, assim, perde-se no mundo 'desvairado' das hipóteses, ficando em meio a sistemas diferentes e opostos. Reduzindo as faculdades da alma ao mesmo órgão, isto é, ao cérebro, a psicofísica, e mais precisamente a frenologia, apressadamente confere às faculdades da alma o mesmo tratamento que se oferece aos órgãos da vista, do ouvido e do olfato, os quais, ainda que separados entre si, jamais tiveram suas sensações concebidas como produção destes órgãos, de seus complementos cerebrais, ou mesmo como produção de diversas faculdades; antes, as sensações resultantes destes órgãos sempre foram atribuídas ao mesmo órgão, no caso, ao cérebro. A insuficiência da psicofísica e os prejuízos que se seguem daí, pois, não ocorrem senão em função do fato de relegarem a ideia de espírito como substância realmente existente, que pensa e se determina na consciência de sua existência, e cujos atos, pensar e querer estão neles mesmos:

O corpo, única coisa que percebemos pelos sentidos, se nos apresenta como extenso, divisível, inerte, sujeito a uma 
contínua mudança pela ação de certos agentes imponderáveis e de certos movimentos, sem os quais a química nada explica. O espírito, ao contrário, se revela a si mesmo, na consciência de seus atos, como simples, idêntico, ativo, sensível, inteligente e livre em suas determinações, elevando-se pela razão ao conhecimento das leis do universo, e do Ser eterno, causa necessária de quem depende (MAGALHÃES, 1867, p. 36).

De fato, se a redução das faculdades da alma a funções cerebrais suprime a unidade e identidade de eu, isso se deve à prévia supressão da inteligência e vontade como seus atributos primordiais e indissociáveis, isto é, ao desconhecimento de que saber já é em si poder, e de que poder é verdadeiramente saber que pode, o que significa, ignorar que saber é inteligência e que poder é vontade livre. $E$, sem dúvida, a grande consequência da orientação que suprime a unidade e identidade do eu mediante a eliminação da inteligência e vontade como atributos inexoráveis da consciência é a subordinação das faculdades morais e intelectuais às leis do fatalismo.

O equívoco procede, pois, da sinonimização que a psicofísica estabelece entre as faculdades intelectuais e morais em relação às sensações, inclinações e instintos humanos, ou seja, da sinonimização entre o que pertence à consciência subjetiva e o que pertence à contextura fisiológica. Natural, portanto, que Magalhães tenha se insurgido contra a crescente tendência em aplicar os estudos de fisiologia e aprendizagem animais no âmbito do comportamento humano. Tal orientação, afinal, se erige a partir de uma equivocada concepção que a leva a estreitar em demasia os laços que se verificam entre a inteligência e as sensações, a partir da crença de que é possível localizar no cérebro as faculdades intelectuais e morais:

Essa unidade e identidade do ser moral que pensa é um fato soberano, e indeclinável, que não perde os seus direitos mesmo perante a fisiologia, e protesta, e protestará sempre contra todas as teorias que pretendem anulá-lo. E, como na explicação dos atos de consciência pôr de lado a condição principal, - a unidade e identidade do Eu? (MAGALHÃES, 1867, p. 3).

A fisiologia, em busca de algum elemento ou agente distinto no cérebro ao qual possa atribuir a responsabilidade pelos fenômenos da consciência, permanece incerta e imprecisa, reconhecendo a impossibilidade de se posicionar em relação à natureza da alma, e contentando-se em decretar o espírito como expressão meramente convencional. Limitada ao estudo empírico das funções do cérebro, por reconhecer a impossibilidade de associar a divisão do trabalho do cérebro à divisão da inteligência, a fisiologia permanece imóvel e 
muda quanto aos fatos que ultrapassam os alcances de suas indagações e experiências. A psicologia, cuja relevância se deve principalmente à capacidade que suas soluções têm de estar na base da solução de outros problemas não menos importantes, reiteradamente comprova sua distância da fisiologia. Prova disso é o fato de que tantos os filósofos quanto os homens comuns sejam levados a atribuir os estados de consciência a um "princípio simples, a um mesmo sujeito indivisível, a que chamamos alma ou espírito", distinguindo-os, destarte, "do princípio substancial dos fenômenos corpóreos, que se nos apresenta como composto de partes e divisível" (MAGALHÃES, 1867, p. 3).

Neste sentido mesmo, o exame das faculdades intelectuais e morais do homem não requer diretamente o conhecimento prévio da natureza substancial do ser que as exerce nem dos órgãos que as sirvam. Afinal, é inteiramente factível o estudo das faculdades da alma a partir do exame da própria consciência, distinguindo-as de todo o resto, e conhecendo a especificidade de cada uma delas e do que resulta de seu conjunto, sem que, para tanto, seja necessário buscar as causas ocultas que as produzem.

Por outro lado, todavia, também é possível o exame dos fenômenos físicos, de suas relações e leis, sem que, para tanto, seja necessário o ingresso na natureza íntima da substância material, isto é, naquela parte que escapa a nossos sentidos e a todos os meios de observação: ainda que sua existência seja inequivocamente admitida e fundamente a crença na existência de uma substância distinta, a que pensa. Com efeito, a psicologia pura permanece reduzida ao estudo dos fatos de que temos consciência, sendo, assim, levada a se calar diante da influência do cérebro e de suas funções, já que o recurso estrito ao uso puro da razão teórica nada lhe revela sobre estes pontos. Em vista da classificação dos atos da consciência, isto é, dos fenômenos de que temos consciência, os psicólogos se propõem elevar às condições ontológicas do ser que as exerce "por um modo tão oculto que escapa à observação" (MAGALHÃES, 1867, p. 3). Já os fisiologistas modernos, em vista do estudo do homem em seu complexo orgânico, e tendo em conta alguns fatos poderosos a seu favor, rapidamente assumem como um fato irrefragável que o exercício das faculdades intelectuais e morais em tudo dependem do cérebro. Ora, mas se "não é com os olhos pregados no mundo exterior, com todos os sentidos abertos e atentos aos fenômenos sensíveis, que há de o espírito humano conhecer sua própria natureza, os seus atributos e o seu destino" (MAGALHÃES, 2004, p. 293), torna-se forçoso defender que a psicologia moderna, pretensamente fisiológica, reivindica um estatuto de cientificidade que não se justifica. Ainda que já não se cogite mais de um sentido alienante e contemplativo de psicologia - que permaneça indiferente à discussão de como as faculdades da alma se relacionam com o 
cérebro - também não se cogita mais de uma posição que esteja alheia à necessidade de conciliação entre filosofia e ciência.

Decerto, a variedade dos atos intelectuais e morais, a classificação psicológica das nossas faculdades, a "natureza das nossas ideias tanto sensíveis quanto racionais, as suas diversas associações, a dependência com que todas se apresentam de um só sujeito idêntico e voluntário" constituem elementos que deixam a fisiologia na completa impossibilidade de separar e localizar as faculdades em diversas partes do cérebro, como propunha a frenologia. Não há, ademais, nada que comprove que ao cérebro possamos legitimamente atribuir algum elemento ou agente distinto responsável pelos fenômenos da consciência. Sem embargo, maior clareza haveria quanto ao estudo do próprio ser caso se lhe juntasse a fisiologia do sistema nervoso, haja vista que, se a fisiologia por si só não é capaz de penetrar a consciência em vista de explicar os mistérios do mundo do pensamento, conhecer a que se reduzem as funções dos nervos e a que se reduzem as funções obscuras do cérebro certamente nos induzirá a uma melhor compreensão das nossas faculdades e da potência livre que as exerce. Contra a orientação que desvincula as faculdades da alma da contextura fisiológica, também diz Magalhães: "os vícios de conformação do cérebro, certas relações entre o volume e a configuração desse órgão, com a perfeição das faculdades do espírito, são também provas em favor dessa opinião" (MAGALHÃES, 1867, p. 26). Ressaltese, porém, isso não exclui a própria liberdade como o fato que mais essencialmente caracteriza a consciência. Contra a orientação estritamente materialista, Magalhães enuncia que a psicofísica:

\begin{abstract}
Encontra completo desmentimento em tudo o que sabemos da matéria, e em nossa própria consciência, que se distingue de tudo o que é material. Se um órgão pudesse pensar e querer, como não saberia ele que exercia esses atos? Se imaginam que o cérebro pode pensar e querer, em saber que é ele que pensa e que quer, do mesmo modo que o estômago digere, e o fígado segrega a biles, sem saber que o fazem, e mesmo se existem; respondo com o fato incontestável que o ser que em nós pensa, sabe que pensa e que existe, e tem consciência de sua simplicidade e identidade; e não se acha no caso do estômago e do fígado e do cérebro que não sabem o que fazem. Por outro lado, o pensamento não é uma matéria transformada, ou segregada, a que se reduzem os produtos de todos os órgãos (MAGALHÃES, 1867, p. 22).
\end{abstract}

Trata-se, pois, do anúncio o qual preconiza veementemente a necessidade de uma nova orientação em filosofia de acordo com a exigência de conciliação entre filosofia e ciência sem que, para tanto, se reduza o espírito a mero mecanismo ou a faculdades cuja 
compreensão prescinda da explicação fisiológica. O prejuízo da psicofísica é latente em função de princípios estruturalmente duvidosos. Quando Magalhães pensa na modernização da "ciência" da alma ou espírito, o que implica a conciliação entre filosofia e ciência, isso não ocorre em prejuízo de seu fundamento no modo do ser do homem concreto e histórico, isto é, a liberdade como princípio de ação, e não a vontade indiferente que caracteriza a liberdade sob a égide da contemplatividade.

\section{A inserção de Tobias Barreto no debate: a crítica à teoria da sensibilidade de Magalhães}

Assim como Gonçalves de Magalhães foi o responsável pela inserção do pensamento brasileiro no cenário do racionalismo espiritualista francês, Tobias Barreto introduziu o pensamento brasileiro na filosofia do neokantismo alemão (Dilthey, Windelband, Rickert, Eduard von Hartmann), tendo sido o primeiro no Brasil a estudar Kant no original. Mas, enquanto a marca característica de Magalhães é a conciliação em relação à tradição, Tobias Barreto, ao introduzir o neokantismo no Brasil, ficou marcado por sua posição crítica em relação ao nosso passado sob a égide do "espiritualismo" de Magalhães, a quem atribuiu o título de tradicionalista: "todos sabem que esta obra, escrita por um homem afeito ao movimento da política e das letras europeias, constitui, ela só, - tal é nosso atraso - toda a biblioteca filosófica do Brasil" (BARRETO, 1966b, p. 22). Sem deixar de reconhecer a tentativa louvável de Magalhães de naturalizar no Brasil a filosofia em nome da ciência e do progresso, Tobias chama para si a tarefa de efetivamente consolidar a mudança de princípio no Brasil, visto acreditar que Magalhães se deixou levar pela presunção de que se pode facilmente engendrar novas teorias e tratá-las como novas, quando, na verdade, o que fez foi "historiar e criticar doutrinas já usadas" (BARRETO, 1966b, p. 22).

Em sua crítica da obra de Gonçalves de Magalhães, Fatos do Espírito Humano, Tobias Barreto reconhece o capítulo VIII como um momento digno de ser examinado, razão pela qual escreveu um artigo homônimo com o intuito de depreender os princípios necessários para modernização e emancipação da cultura brasileira de "ideias frágeis" da teoria da sensibilidade de Magalhães. A teoria da sensibilidade de Magalhães é, para Tobias, "a sustentação da antiga tese que tira a sensibilidade da alma para atribuí-la a um princípio diverso", em vista da "solução do grande problema da união e distinção da alma e do corpo", o que levou "cada filósofo a inventar uma hipótese" (BARRETO, 1966b, p. 24). Segundo seu entendimento, à tese de Magalhães - de que a vida não é efeito da alma nem do corpo, mas uma força distinta à qual se atribui a sensibilidade, de maneira que as sensações estariam a priori "na faculdade de sentir" e dependendo apenas de um estímulo para se manifestarem - deve-se contrapor o 
argumento de que, se a sensibilidade é uma propriedade vital, nada justifica a existência de outro estímulo para sua atualização, mas apenas seu desenvolvimento natural:

\begin{abstract}
Com efeito, se o princípio vital é quem organiza o corpo, como o autor admite, pois que o organismo conserva-se e desenvolve-se por meio de funções, é claro que estas são dirigidas ou presididas, se não exercidas pelo mesmo princípio. Ora, basta notar que as funções da vida vegetativa são contínuas; a continuidade é sua condição normal, sob pena de produzir-se o dessaranjo na economia e dar lugar à doença e à morte (BARRETO, 1966b, p. 25).
\end{abstract}

Segundo Tobias, no que diz respeito ao homem, temos que afirmar não só que sente, mas que também é capaz de sentir. Assim como sabemos que os nervos são capazes de se contrair, bem como a razão pela qual se contraem e enquanto se contraem, não podemos dizer que sabemos que somos capazes de sentir, a razão pela qual sentimos e enquanto sentimos. O que se segue daí, ensina-nos Tobias, é que temos consciência da sensibilidade não só em ato, mas também em poder; da mesma forma que a consciência só dá conta das faculdades espirituais, ela também dá conta da sensibilidade. Por isso mesmo, não podemos atribuir, como fizera Magalhães, a sensibilidade à força vital, mas à própria alma. Ora, se a sensibilidade não é uma faculdade da alma, como propõe Magalhães, e se é o ouvido o órgão da inteligência pura, "como é que um de seus modos só se presta ao que é puramente da mesma alma pensante, e não concorre em nada com a força vital, a que pertence, para o vasto trabalho da organização do corpo?" (BARRETO, 1966b, p. 24). Esta é, de acordo com Tobias, uma inconsequência que deve ser prevenida. Aceitando a proposta kantiana de estabelecer o fenômeno como limite do saber científico, Tobias considera a predileção de Magalhães como contrária aos ensinamentos da experiência, razão pela qual considera o espiritualismo de Magalhães como a face psicológica do tradicionalismo: "a força vital do nosso filósofo [Magalhães] merece mais que uma simples menção da ciência; merece cantos da poesia, já que é uma espécie de fada, silfo ou gnomo que se alimenta de aromas. O achado é imenso" (BARRETO, 1966b, p. 29).

Para Tobias, a sensibilidade é incontestavelmente uma faculdade da alma pensante, e não de um terceiro elemento, pois é o que requer a unidade da consciência e a harmonia total da vida humana: "de onde vem a virtude de certos atos que custam dores, se a sensação não é psíquica, se estas dores não são da alma?" (BARRETO, 1966b, p. 30). Ora, é a consciência moral que deve apreciar os diversos motivos de sua ação para julgar com acerto, conhecendo todos em sua natureza, de modo que assim possa fazer opções reais, ao invés de manter-se indiferente na escolha dos contrários. A questão que Tobias então 
estabelece é a seguinte: "se na consciência não entra o prazer mesmo, mas apenas a sua noção, como quer o nosso autor, em que se funda a distinção moral do prazer e do dever, bem como a distinção psicológica de prazeres e dores?" (BARRETO, 1966b, p. 32). $\mathrm{O}$ erro de Magalhães teria sido, pois, o de considerar que o princípio que pensa não é o mesmo que sente. Assim, Magalhães seria obrigado a considerar que o triunfo de conquistar dolorosas vitórias sobre si mesmo pelo vigor da vontade deveria ser creditado à sensibilidade, e não à alma. Daí porque o espiritualismo de Magalhães compromete-se consigo mesmo. Tal é a razão porque um dos grandes e grosseiros erros da psicologia consiste em dar como fatos incontestáveis da consciência princípios duvidosos, "elevando-se assim a induções forçadas", de onde depreende "argumentos gerais de exceções ou de experiências que nada autorizam, poetiza, declama e afinal constitui uma ciência imaginária. Tal defeito caracteriza a obra do nosso filósofo" (BARRETO, 1966b, p. 32).

Em última instância, a tarefa primordial de Tobias é a de combater a aspiração espiritualista de imprimir às suas pesquisas e ideias o caráter verdadeiramente científico, isto é, a crença de que "empregaram no estudo do homem e do mundo intelectual o método praticado com tanta vantagem no estudo do homem e do mundo material" (BARRETO, 1966a, p. 4). É neste contexto que Tobias denuncia o espiritualismo, o qual, crendo atingir com veracidade os postulados de uma "ciência da alma" a partir do conceito moderno de verdade científica, acabou por viciar a psicologia desde seus princípios. A questão que permanecera aberta em Magalhães é a seguinte: por um lado, é preciso pensar uma psicologia que seja capaz de salvaguardar a liberdade do indivíduo, sendo preciso, para tanto, dar conta dos argumentos inerentes à psicologia experimental quanto à impossibilidade de ações livres diante do mecanismo da corporeidade e do fatalismo. Por outro lado, porém, tal tarefa não pode deixar de dar conta que a individualidade real supõe a existência de um corpo o qual nos mantém presos à necessidade e às determinações universais das leis da natureza. Sem dúvida, esta individualidade real, que supõe a união de alma e corpo, também implica uma consciência e uma liberdade que oferece ao indivíduo a posse de si mesmo, por meio da qual o indivíduo diz eu certo de que realmente existe.

\section{A "psicologia viva dos artistas": o diálogo de Tobias Barreto com a Psicologia Científica e a crítica ao espiritualismo}

Tal questão é, de fato, um dos pontos centrais da análise de Tobias Barreto, para quem "desde Sócrates até os nossos dias, a consciência humana tem sido interpelada, e todavia as suas respostas ainda não enchem meia folha de verdades. Não basta reconhecer e alegar a existência dos fatos internos" (BARRETO, 1966c, p. 82). Tal vício, 
decerto, reside em toda proposta de buscar para o mundo espiritual as leis, causas e forças que valem para a observação do mundo material. Eis as origens das falaciosas teses de que o eu é a primeira causa que conhecemos, e de que a psicologia, e não a mecânica, é a verdadeira ciência das forças. Com efeito, se o primeiro fato da consciência não pode ser concebido como fenômeno - já que sua substância não escapa ao conhecimento imediato - esclarece-se a razão pela qual a psicologia não pode reivindicar para si o mesmo método empregado pelas ciências naturais. O grande prejuízo do materialismo quanto à simplicidade e espiritualidade da alma, pois, foi legitimado pelo próprio erro de método dos espiritualistas, isto é, por não terem reconhecido a existência do eu substancial como uma intuição da consciência. Em que sentido o espiritualismo deu passagem ao materialismo e ao cepticismo? Certamente, em função dos psicólogos do século XIX terem feito da "substância do eu uma coisa obscura e problemática, para terem o prazer de aplicar o telescópio do seu método e dizer enfim: a alma é espiritual" (BARRETO, 1966a, p. 5).

Ademais, se os fatos internos são realmente incontestáveis, de tal ordem que não só fazem parte da vida, mas se confundem com a vida mesma, a escola espiritualista busca seu ponto de partida em ideias comuns que nada acrescentam, como a tese de que a psicologia trata de fatos evidentes na mesma medida que diferem dos sentidos: "é um defeito habitual a todo espiritualista, o de julgar-se obrigado a não discutir assunto filosófico sem uma introdução de ideias muito vulgares, que não trazem luz para o debate" (BARRETO, 1966c, p. 82). Um dos mais cegos enganos da psicologia espiritualista, afirma Tobias, é a crença de que é possível sempre recorrer à observação imediata para reproduzir o fato que se pretende estudar. Afinal, em tal noção está implícita a mesma ideia que, justificadamente, norteia as ciências naturais, a saber, a pretensão de também se basear na experiência, quando é justamente esta possibilidade o que falta à psicologia pura. São as ciências positivas que têm a vantagem de pôr a seu serviço os órgãos dos sentidos e aparelhos especiais. É neste sentido que nada justifica a ideia dos seguidores de Descartes de que a consciência basta para dizer o que se passa no fundo da vida moral. Sem se comprometer com a posição de Comte, muitos são os motivos, de acordo com Tobias, que legitimam a dúvida quanto à eficácia de todos os meios da psicologia espiritualista em tentar fazer com que o homem se conheça de modo objetivo e científico: "colocando-se em face do eu - nu e solitário, nunca pode tomar a verdadeira atitude de um observador" (BARRETO, 1966c, p. 83). Ora, qualquer enunciado que se proponha fazer da alma um objeto de estudo deve supor sua visão em "estado natural, entregue a si própria, segundo somente a marcha traçada pela lei de sua existência" (BARRETO, 1966c, p. 84). 
Nesse sentido, as pretensões da psicologia espiritualista não se justificam em função mesmo do fato de que a objetivação da alma requer o "eclipse" do senso íntimo enquanto órgão infalível de observação, o que, como se sabe, é um grande contrassenso.

Para os que creem que os fatos da vida interna podem ser observados de modo a fornecer matéria científica, a consciência nos dá conhecimento do mundo interior do mesmo modo que os sentidos nos oferecem conhecimento do mundo exterior: "o que em última análise quer dizer somente que consciência é consciência" (BARRETO, $1966 c$, p. 82). Para fins científicos, dizer que consciência é consciência é pouco, já que, nesta questão, relevante é saber se, quando o homem se volta sobre si mesmo para observar-se pensando, realmente encontra o que procura. Mas, com efeito,

\begin{abstract}
Não há fenômeno mais vulgar do que ver o psicólogo entrar, como ele diz, no fundo de seu ser, a fim de buscar a base de todo conhecimento humano. Nesse intuito, é natural que ele simule duvidar de tudo, exceto o pensamento. Pelo menos é este o sentido do famoso, bem que estéril, cogito ergo sum. Tenhamos porém coragem para proclamá-lo desde já: estas fórmulas vazias não aguentam uma análise severa (BARRETO, 1966c, p. 84).
\end{abstract}

De acordo com Tobias, portanto, nada garante que a consciência seja fiel intérprete do mundo interior, visto estar sempre sujeita a "uma ou outra sombra imaginária" que acaba por alterar os resultados da imaginação. Eis o engano: a crença de que a experiência dos fatos internos tem o mesmo estatuto que a experiência repetida a qual, no âmbito das ciências naturais, assegura a garantia da positividade do saber. É deste engano que advém a ideia de que não cabe à psicologia ingressar em pontos isolados por ter a obrigação estrita de lidar com fenômenos gerais: "ninguém concebe uma ciência, dita experimental, que ponha de lado, sob o pretexto de raridade, negócios da sua alçada" (BARRETO, 1966c, p. 87). Ainda que as pretensões da psicologia espiritualista sejam modestas a ponto de considerar que a psicologia deva se restringir às potências do espírito, nem assim suas aspirações são alcançadas, tendo em vista a impossibilidade de se conceber que "as faculdades até hoje e desde há muito conhecidas" podem, em alguma instância, esgotar "as riquezas potenciais da alma humana": "como penetrar nesses tesouros ocultos, entranhados no fundo da vitalidade orgânica, por meio da consciência?" (BARRETO, 1966c, p. 88).

O que ocorre, em verdade, é que as descobertas da psicologia espiritualista não ultrapassaram o reconhecimento de algumas faculdades que só acrescentaram a certeza de uma inteligência e de uma vontade. Mas não é por serem invisíveis e impalpáveis, afirma Tobias, o motivo pelo qual os fatos da consciência são incapazes de 
oferecer matéria científica e de estarem dispostos em uma ordem metódica: "que importa a realidade dos fenômenos internos se ela não admite uma observação regular?" (BARRETO, 1966c, p. 90). Aquilo que se tem em vista na ciência não se pode buscar e afirmar sem muito erro e engano na psicologia:

\begin{abstract}
Querer achar na consciência do indivíduo o reflexo de todas as modalidades da espécie é uma pretensão quimérica. A psicologia me parece condenada, por sua natureza, a não ter um voto sequer no grande conselho das ciências. Basta advertir que ela é impotente para fornecer os mais simples dados de uma previsão. Ora, uma ciência de fatos naturais, imprevidente, é coisa que não acha apoio na razão de um homem despreocupado (BARRETO, 1966c, p. 90).
\end{abstract}

Se Tobias Barreto, por um lado, não podia adotar os princípios dos defensores da psicologia de cunho racionalista, na linha do espiritualismo de Cousin e Jouffroy, então em voga no Brasil, por outro, as objeções dos empiristas ao espiritualismo não o levaram a se convencer quanto à ideia de psicologia como ciência: "a psicologia empírica, a despeito de todas as suas descrições e pinturas do mundo subjetivo, ainda nada pôde levantar que seja traduzível em forma científica" (BARRETO, 1966c, p. 90). Daí a razão pela qual Tobias julga "imperdoável essa facilidade que tem a psicologia de prometer muito, para dar tão pouco. Não sei mesmo como ainda se possa insistir na ideia de uma ciência de tal guisa" (BARRETO, 1966c, p. 92). Em comum, ambos, espiritualistas e defensores de uma psicologia empírica, crendo, apressadamente, que a psicologia está viva e prossegue em sua marcha, não hesitam em partir da indução para estabelecer como lei geral aquilo que mal pode observar em si mesmo.

A psicologia viva dos artistas se mostra mais eficiente que a psicologia justamente por não se basear em qualquer espécie de intuição psicológica, pois a vida interna dos indivíduos, em sua riqueza, está para além do alcance de nossas indagações. Se há fenômenos e movimentos que, aparentemente, escapam aos cálculos e preceitos da filosofia, não se segue daí que tais fenômenos não sigam certas leis, mas antes, que estas leis não foram e não podem ser descobertas jamais: "não sabemos discernir o verossímil do verdadeiro. Tal é o erro daqueles que levam em conta, a bem da psicologia, as excursões dos poetas nos obscuros domínios da possibilidade indefinida, em busca dos segredos mais recônditos do espírito" (BARRETO, 1966c, p. 96). Eis, portanto, uma grande lacuna inerente a qualquer "ciência da alma", a despeito de oferecer as mais seguras garantias de exatidão e validade: a "ciência da alma" é, assim, "pouco apta para dar-nos, sem qualquer exagero, uma história verdadeira de sua subjetividade" (BARRETO, 1966c, p. 96). 
A questão que se impõe, diante deste quadro, é a seguinte: como admitir uma "ciência da alma" que nunca nos leva ao saber não apenas nas causas, mas também nas simples relações dos fatos? Ora, o astrônomo, mostra Tobias, sabe e pode representar, à luz da razão, a marcha regular dos fenômenos siderais, do mesmo modo que o médico sabe que um outro sintoma ocorre em função de um outro desarranjo. O psicólogo, ao contrário, "gira em uma esfera tenebrosa, em uma região de espectros e visões inconscientes" (BARRETO, 1996c, p. 97). Embora ninguém possa negar a ordem cotidiana dos fatos subjetivos, deles a psicologia não retira o menor proveito. Daí Tobias afirmar que, na psicologia, há total carência de dados para se formarem "exatas e profundas previsões", de sorte que a psicologia não descobre uma só das leis que determinam a formação do indivíduo:

Eu já o disse: - o defeito capital da psicologia, como ciência de observação, é a falta absoluta de dados para se formarem exatas e profundas previsões. O mundo físico, em seu vasto e intrincado arranjo, pode sempre causar admiração, ainda mesmo aos espíritos mais cultos; - porém não causa espanto (BARRETO, 1996c, p. 98).

\section{A ilusória "ciência do eu" de acordo com Tobias Barreto}

Ora, esse espanto suscitado pela magnanimidade da natureza é sucedido pela ordenação, isto é, por um produto da inteligência por meio do qual a harmonia e a razão das coisas se estabelece no mundo natural. O que ocorre, todavia, é que esse mesmo produto não tem o menor alcance no âmbito do mundo moral, em que os homens, por meio de palavras e ações, sempre nos assombram com algum recanto do "coração" que antes nos era desconhecido. Tal é a prova da irrefragável ignorância quanto à ordem e às leis que habitam os domínios do espírito:

\footnotetext{
Não canso de repeti-lo: a ciência do eu implica contradição. Abstraído da pessoa, e do caráter que a constitui, o eu é coisa nenhuma, nada significa. Mas onde estão as induções científicas, feitas de modo que possam garantir nossos juízos sobre a marcha normal da personalidade alheia? Eu disse alheia; e pudera dizer própria. Todos nós sabemos, por experiência, que as mais das vezes, o que nos desarranja e nos perturba, no curso ordinário da vida é a ignorância de nós mesmos, da força de nossas paixões, ou da fraqueza de nossa vontade (BARRETO, 1966c, p. 99).
}

A ilusória ciência do eu se agita em meio a uma série de erros que comprovam estar a psicologia diante apenas de um suposto e infundado conhecimento do homem, crendo, ingenuamente, surpreendê-lo no retiro de sua consciência. Ora, se há uma razão que 
justifique tanto erro no cálculo humano acerca das leis inerentes às relações sociais, isso se deve ao fato de as almas nunca se conhecerem mutuamente. Muitos foram, segundo Tobias, os que se propuseram medir toda a extensão do seu ser e, após milhares de anos, a ciência da alma ainda busca constituir-se e organizar-se, estando ainda em posição insuficiente para oferecer ao homem uma noção menos ambígua de si mesmo.

Qual é, pois, o estatuto dos trabalhos de observação subjetiva? De acordo com Tobias, não são de todo rejeitáveis, desde que, todavia, sejam concebidos como estudo, como entretenimento, e jamais como ciência. No âmbito desta noção talvez seja possível adquirir noções mais claras do papel e do jogo mútuo das faculdades. A afirmação da busca por noções mais claras, ressalte-se, não significa decretar a infalibilidade do cogito cartesiano. Tal fórmula, cuja ingenuidade se deve à mesma razão pela qual jamais houve a necessidade de refutála, esconde por trás de si uma grande omissão de toda escola espiritualista, a saber: definir a existência de uma real identidade entre a proposição eu sou pensante e a proposição eu sou espírito. Seria preciso definir se a proposição eu sou pensante legitima a ideia de que tenho uma alma substancial e distinta do corpo. Contra espiritualistas e empiristas, Tobias considera que a pretensão de espírito real e separado da matéria é sempre questão aberta, insolúvel tanto pelo método introspectivo quanto pelo método das ciências naturais. Assim, a tese de que a alma tem consciência de si mesma, de que se observa melhor prescindindo dos cinco sentidos, de que suas propriedades são inteiramente distintas da matéria, bem como as que defendem sua identidade e unidade é a um só tempo tratada pelos psicólogos como ponto de partida e como questão. Tais suposições, triviais e inquestionáveis, melhor seriam equacionadas se fossem formuladas nos seguintes termos: "a consciência é um grau superior da evolução da matéria, ou é própria e somente própria de um ente unido ao corpo, e ao qual se dá o nome de alma?" (BARRETO, 1966c, p. 105). Com efeito, ilógico e despropositado seria o pensamento de uma consciência que não tenha consciência de si, e nada acrescenta o pensamento da consciência que tem consciência de si. Ora, "se ela é a faculdade que o homem possui de conhecer-se internamente na parte superior das funções mentais, por que razão exerceria outro mister?" (BARRETO, 1966c, p. 106). Nada legitima, crê Tobias, que do reconhecimento da consciência como parte integrante da parte superior das funções mentais se siga uma tese sem dados que a fundam, isto é, uma tese que proclame a existência de duas substâncias no homem.

Se o espiritualismo se funda em suposições triviais, o propósito de uma psicologia científica incorre no grave erro de supor uma analogia entre os fatos da percepção interna e o que dizem respeito ao corpo, ou seja, tudo o que é percebido pelos sentidos: "não vejo razão de 
maior pasmo em julgar a matéria organizada de modo a produzir os fenômenos intelectuais". Certamente, "quando se fala na matéria, ocorre-nos de pronto uma série de objetos físicos, os mais rudes e mais baixos que possa imaginar [...]. Quem poderá admitir que o pensamento brote de semelhante argila?!" (BARRETO, 1966c, p. 107). Por outro lado, as suposições, de cunho espiritualista, resumindo-se todas à ideia de que o pensamento só pode residir no espírito, e principalmente de que há uma incompatibilidade absoluta entre espírito e matéria, confundem uma suposição com aquilo que está em jogo, o que decerto resulta naquilo que os lógicos chamam de círculo vicioso. Segundo Tobias, a tese magna do espiritualismo ao qual adere Gonçalves de Magalhães, resultante de uma suposta observação imediata da inconteste existência da alma espiritual, e erguida com aparência de grande e laboriosa empresa, jamais vem acompanhada dos supostos argumentos que a tornam uma evidência indiscutível: "não é sem muita razão que se lhes atribui o quererem impor-nos esta sua hipótese a título de dogma" (BARRETO, 1966d, p. 85). E é neste termo que mais precisamente reside a consolidação de uma mudança na maneira de pensar, quando Tobias, profeticamente, anuncia uma nova era, em que o espírito humano,

Considerado em suas eminências, lança ao desprezo o resto dos brinquedos de sua infância. É a queda do último véu que ainda nos oculta muita verdade santa, apenas pressentida pelos raros eleitos da ciência, cruelmente imparcial como a natureza (BARRETO, 1966c, p. 108).

\section{Considerações Finais}

Com efeito, ainda que Gonçalves de Magalhães e Tobias Barreto tenham rejeitado a pretensão e reivindicação naturalistas, e ainda que Tobias tenha assumido uma posição frontal ao espiritualismo de Magalhães, a filosofia brasileira, desde então, soube reconhecer, em uníssona voz, que a pretensão naturalista muito contribuiu, historicamente falando, para o necessário resgate da ideia de uma 'ciência do espírito' do âmbito da teologia, sem prejuízo da noção de que nossos conhecimentos são limitados justamente por não compreendermos tudo mecanicamente, isto é, segundo o método das ciências da natureza. Eis a delimitação filosófica da questão: se, por um lado, é preciso, modernamente, aceitar o limite dos métodos matemático-experimentais como condição de toda a transcendência, mais necessária ainda é a tarefa de salvaguardar a dimensão psíquica da liberdade dos atos humanos.

\section{Referências Bibliográficas}

BARRETO, T. Guizot e a escola espiritualista do século XIX. In:

Estudos de filosofia. Rio de Janeiro: Instituto Nacional do Livro, $\bar{p}$. 
03-08, 1966a.

BARRETO, T. Fatos do Espírito Humano. In: . Estudos de filosofia. Rio de Janeiro: Instituto Nacional do Livro, p. 22-33, 1966b.

BARRETO, T. A ciência da alma ainda e sempre contestada. In: Estudos de filosofia. Rio de Janeiro: Instituto Nacional do Livro, p. 80-108, 1966c.

BARRETO, T. Glosas heterodoxas a um dos motes do dia, ou variações anti-sociológicas. In: __--. Estudos de filosofia. Rio de Janeiro: Instituto Nacional do Livro, p. 29-76, 1966d.

CERQUEIRA, L. A. Filosofia brasileira: Ontogênese da consciência de si. Petrópolis: Vozes, 2002.

- Farias Brito como expressão da identidade filosófica brasileira.

In: BRITO, R. F. O Mundo I nterior: Ensaio Sobre os Dados Gerais da Filosofia do Espírito. Lisboa: Imprensa Nacional Casa da Moeda, 2006.

MAGALHÃES, D. J. G. A alma e o cérebro: Estudos de psicologia e fisiologia. 3. ed. Rio de Janeiro: Garnier, 1867.

Fatos do espírito humano. 3. ed. Petrópolis: Vozes, 2004.

\section{Endereço para correspondência:}

Leonardo Ferreira Almada

Faculdade de Filosofia, Universidade Federal de Goiás, Campus II, Samambaia, Caixa postal 131, Goiânia - GO, Brasil

Endereço eletrônico: leonardo.f.almada@gmail.com

Luiz Alberto Cerqueira

Instituto de Filosofia e Ciências Sociais da Universidade Federal do Rio de Janeiro, Largo de São Francisco, 1, Sala 325C, Centro, CEP 20051-070, Rio de Janeiro-RJ, Brasil

Endereço eletrônico: cerqueira@ifcs.ufri.br

Recebido em: 06/11/2009

Aceito para publicação em: 02/03/2010

Acompanhamento do processo editorial: Rita Maria Manso de Barros

\section{Notas}

* Pós-Doutorado pelo Instituto de Biociências da Universidade Estadual Paulista "Julio Mesquita Filho" - UNESP, Botucatu, SP, Brasil; Doutor e Mestre em Filosofia pelo Programa de Pós-Graduação em Filosofia da Universidade Federal do Rio de Janeiro; Bacharel em Filosofia pela Universidade Federal do Rio de Janeiro. 